\title{
Puuvartisten viherrakentamisen kasvien erikoismuotoja pohjoiseen, esimerkkinä punakoivu (Betula pubescens f. rubra)
}

\author{
Henna Pihlajaniemi \& Mirja Siuruainen \\ Oulun yliopiston kasvitieteellinen puutarha, PL 3000, 90014 Oulun yliopisto \\ etunimi.sukunimi@oulu.fi
}

\section{Tiivistelmä}

Puista ja pensaista tavataan toisinaan kasvutavan, lehtien värin tai muodon, tai kukkien värin tai kerrannaisuuden suhteen alkuperäisestä lajista poikkeavia yksilöitä. Nämä erikoismuodot ovat arvokkaita sekä tieteellisen tutkimuksen että käytännön viherrakentamisen kannalta. Oulun yliopiston kasvitieteellisessä puutarhassa kasvaa lukuisia tällaisia muotoja ja lajikkeita. Punalehtisiä taksoneita ovat esimerkiksi punakoivu (Betula pubescens f. rubra) ja punaharmaaleppä (Alnus incana f. rubra). Koivuista kasvavat myös liuskalehtinen loimaankoivu (B. pendula f. crispa) sekä pensasmainen rauduskoivu. Myös harmaalepästä kasvaa pensasmainen muoto. Kasvutavaltaan pylväsmäisiä muotoja on mm. pihlajissa. Tuomesta kasvitieteellisessä puutarhassa kasvaa kaunis kertokukkainen muoto (Prunus padus f. plena). Havukasveista on useita kasvutavaltaan tai väritykseltään peruslajeista eroavia muotoja hopeakuusesta (Picea pungens f. glauca) mattomaisiin kääpiökatajiin.

Tunnetuin lehtipuun erikoismuoto pohjoisessa Suomessa lienee punakoivu, joka löydettiin vuonna 1978 Ylikiimingistä. Tämä hieskoivun muoto onnistuttiin mikrolisäämään Oulun yliopistolla 1980-luvun lopulla, jonka jälkeen se alkoi yleistyä viherrakentamisen kasvina. Kaikki istutetut puut ovat yhden ja ainoan luonnossa kasvavan puun kasvullisesti tuotettua jälkeläistöä. Emonpuu ei tuohon aikaan tuottanut siemeniä, mutta mikrolisättyihin puihin muodostuu toisinaan itämiskykyisiä siemeniä. Punakoivun lehdet puhkeavat heleän vihreinä, tosin lehden reunat ovat jo hiirenkorvalla tummanpunaiset. Silmusuomut ovat kauniin tummanpunaiset. Punainen väriaine leviää nopeasti koko lehteen sen auetessa täyteen mittaansa. Lehden punainen ulkoasu johtuu sen pintakerroksessa eli epidermissä olevista antosyaanipigmenteistä. POHKAS (POHjoisen kestävät KASvit) kenttäkokeissa puun fenologiaa ja menestymistä on tutkittu pohjoisimmillaan Sallan Naruskassa asti. Viherrakentamisen kannalta puu on kestävyytensä vuoksi arvokas erikoismuoto pohjoisessa Suomessa. Se on saavuttanut suosiota viherrakentamisen kasvina myös Ruotsissa. Tieteellisessä tutkimuksessa puuta käytetään selvitettäessä antosyaanien toiminnallista roolia pohjoisissa puuvartisissa kasveissa.

Asiasanat: antosyaani, erikoismuoto, kasvitieteellinen puutarha, punakoivu, viherrakentaminen 


\section{Johdanto}

Puuvartisista kasveista löytyy toisinaan yksilöitä, jotka poikkeavat alkuperäisestä lajista esim. kasvutavan, lehtien värin tai muodon, kukkien tai hedelmien värin suhteen. Nämä erikoismuodot ovat kasvin perintötekijöissä tapahtuneen poikkeaman, mutaation seurausta. Mutaatio voi olla tapahtunut sukusoluissa, jolloin koko kasvin soluissa on muuttunut geneettinen koodi, tai silmussa, jolloin erikoisominaisuus ilmenee vain tietyssä osassa kasvia (Oskarsson \& Nikkanen 2001). Erikoismuodot ovat arvokkaita sekä tieteellisen tutkimuksen että käytännön viherrakentamisen kannalta. Niiden avulla voidaan tutkia tietyn ominaisuuden periytymistä tai geneettistä säätelyä kasveissa (Kauppi \& Ulvinen 1989). Koristekasveina erikoismuodot sopivat elävöittämään kasviryhmiä. Ne ovat usein hidas- tai pienempikasvuisia kuin perusmuodot ja sopivat hyvin kaupunkimaiseen ympäristöön. Erikoismuotojen kasvupaikkavaatimukset ovat yleensä samankaltaisia kuin perusmuodoilla.

Kasvisystemaattisesti määriteltynä muoto (forma, f.) poikkeaa lajista yhden tai muutaman ominaisuuden verran eikä sillä yleensä ole selvää yhtenäistä levinneisyyttä. Muunnos (varietas, var.) eroaa lajista muutaman ominaisuuden verran ja sen levinneisyys on rajoitettu (Hämet-Ahti ym. 1992). Koska erityisominaisuuden aiheuttava poikkeavuus on yleensä resessiivinen, erikoismuotoja lisätään tavallisesti kasvullisesti esim. pistokaslisäyksellä, varttamalla tai mikrolisäyksellä. Monia kasvien erikoismuotoja tunnetaan viljelylajikkeina. Lajike on tavallisesti yhtä ainoaa kloonia eli peräisin yhdestä ainoasta yksilöstä, mutta siihen voi kulua myös muutama hyvin samankaltainen klooni (Hämet-Ahti ym. 1992)

Oulun yliopiston kasvitieteellinen puutarha on 1980-luvun puolivälistä lähtien ollut mukana pohjoiseen viherrakentamiseen ja erityisesti sen kasveihin liittyvässä tutkimuksessa. Tutkimusprojektin 'Kasvivalikoiman monipuolistaminen ja taimimateriaalin laadun parantaminen taimitarhatuotannon ja viherrakentamisen tarpeisiin' tuloksena rekisteröitiin kestäviä puuvartisia kasveja pääosin Oulun läänin alueelta, ns. POHKAS (POHjoisen kestävät KASvit)-rekisteriin, jonka sijoituspaikka on kasvitieteellinen puutarha. Rekisteriä täydennetään mm. luonnossa liikkujien ja puutarhaharrastajien ilmoittaessa mielenkiintoisista kasvihavainnoista puutarhaan. Puuvartisia POHKAS-kasveja, joiden aloitusmateriaali on mikrolisätty Oulun yliopiston kasvitieteellisessä puutarhassa, on vuoden 1990 jälkeen toimitettu taimistoille myyntiin n. 60 kantaa. Tunnetuin niistä lienee hieskoivun punalehtinen muoto punakoivu (Betula pubescens f. rubra ). Puutarhan avomaan kokoelmien kasveja on kartoitettu Nikolai ja Ljudmila Borisoffin Puutarhasäätiön rahoittamana kestävien kantojen ja mahdollisten uusien viherrakentamisen kasvien löytämiseksi (Siuruainen ym. 2004). Eräitä puuvartisia erikoismuotoja, esimerkiksi lamoavakasvuinen lettopaju (Salix myrsinites 'Kittilä), on lisätty, tai ainakin suositeltu, pohjoisten matkailualueiden viherrakentamiseen soveltuviksi (Laine ym. 2007).

\section{Pohjoisessa kasvavia erikoismuotoja}

Oulun yliopiston kasvitieteellisen puutarhan 800 puuvartisen taksonin (Laine \& Siuruainen 2008) joukossa kasvaa noin 60 puiden ja pensaiden erikoismuotoa. Valtaosa niistä on taimistoista hankittuja ja yleisesti tunnettuja viljelylajikkeita. Osa on kasvatettu muista kasvitieteellisistä puutarhoista tulleesta lisäysmateriaalista, osan aloitusmateriaali on kerätty muualla pohjoisessa Suomessa kasvavista kasveista, joko puutarhoista tai luonnosta. Osalla erikoismuodoista on käyttöarvoa viherrakentamisen kasvina ja osalla enemmän, kuriositeettina, tieteellisen tutkimuksen näkökulmasta.

Huomiota herättävimpiä erikoismuotoja ovat kasvit, joiden lehtien väri on poikkeava. PohjoisSuomessa viherrakentamisessa suositun punakoivun voimakkaan tummanpunainen väri pysyy lehdissä koko kasvukauden ajan. Voimakkaan punainen väri on myös hurmehappomarjalla (Berberis $\times$ ottawensis 'Superba') ja purppurahappomarjan (B. thunbergii) lajikkeilla 'Atropurpurea' ja 'Atropurpurea Nana'. Viimeksi mainitulla on lisäksi matala kasvutapa. Myös purppuraheisiangervo (Physocarpus opulifolius 'Diabolo') sekä Latviasta tuotu tuomi Prunus padus 'Novosibirskaja' ovat voimakkaan punalehtisiä koko kesän. Purppuratuomen ( $P$. padus 'Colorata') lehdet ovat punavihreät ja kukat vaaleanpunaiset. Osalla punalehtisistä kasveista punainen väritys on voimakkaimmillaan alkukesästä, mutta lehdet muuttuvat vihertäviksi kasvukauden edetessä. Tällaisia ovat mm. Pohjois- 
Karjalasta löydetty punaharmaaleppä (Alnus incana f. rubra), purppuraomenapuu (Malus Purpurearyhmä 'Marjatta') sekä punapähkinäpensas (Corylus avellana 'Atropurpurea'), jotka ovat menestyneet hyvin kasvitieteellisessä puutarhassa. Eteläisessä Suomessa suosittu hurmevaahtera (Acer platanoides 'Faassen's Black') menestyy Oulun korkeudella vaihtelevasti. Paikallisissa taimistoissa myydään suojaisille paikoille istutettavaksi myös verivaahteraa (A. platanoides 'Schwedleri') ja lukuisia punalehtisiä omenapuulajikkeita.

Kelta- tai kellertävälehtisiä erikoismuotoja kasvaa puutarhalla vähemmän. Niitä ei myöskään ole pohjoisilla taimistoilla yleisesti myynnissä. Keltaisuus johtuu klorofyllin vähäisestä määrästä muihin pigmentteihin nähden (Oskarsson \& Nikkanen 2001). Useimmiten keltainen väritys on voimakkaimmillaan nuorissa lehdissä tai versoissa, kuten keltaheisiangervolla (Physocarpus opulifolius 'Luteus'), kultamännyllä (Pinus sylvestris f. aurea) sekä kultakoivulla (Betula pendula f. aurea). Kirjavalehtisyys johtuu lehtivihreän vähäisyydestä tai puutteesta tietyissä osin lehteä. Tämä ominaisuus näyttää tosin osalla kasveilla olevan kasvupaikkaan sidottu, eikä kirjavuutta näy enää lisätyissä kasviyksilöissä (Ryynänen \& Aronen 2007). Kirjavalehtisistä kasveista laikku- ja keltakirjokanukka (Cornus alba 'Elegantissima' ja C. a. 'Gouchaultii') menestyvät Oulun korkeudella suojaisella kasvupaikalla. Kasvitieteellisessä puutarhassa kasvaa myös puistosyreenin (Syringa $\times$ henryi) kirjavalehtinen muoto, joka on saatu Pyhäjärveltä.

Liuskalehtiset puut ja pensaat ovat kasvutavaltaan siromman näköisiä kuin niiden perusmuodot. Koska näiden lehdissä on vähän yhteyttävää pinta-alaa, tulisi kasvupaikan olla valoisa (Kiuru 2006). Lehtien liuskaisuus vaihtelee eri muodoilla ja lajikkeilla. Esimerkiksi taalainkoivun (Betula pendula 'Dalecarlica') lehdet ovat syvempään liuskoittuneita kuin loimaankoivun (B. p. f. crispa). Liuskalehtisiä muotoja puutarhalla kasvaa myös lepistä (Alnus). Taivalkoskelta on luonnosta löytynyt sulkaharmaaleppä (A. incana f. laciniata) ja Kuhmosta hapsuharmaaleppä (A. i. f. angustissima). Hapsumaisesti liuskoittuneet lehdet ovat sulkahernepensaalla (Caragana arborescens 'Lorbergii') ja walkerinhernepensaalla (C. a. 'Walker'). Erilaisia liuska- ja hapsulehtisiä lajikkeita on hyvin saatavilla pohjoisista taimistoista. Lehtien suhteen erikoinen puu on myös riepukoivu (B. pubescens $\mathrm{f}$. hibernifolia), jota leikkisästi kutsutaan "talkkarin unelmaksi". Tämä Ylikiimingistä löydetty koivu ei nimittäin pudota tavalliseen tapaan lehtiään syksyllä (Kauppi \& Ulvinen 1989).

Osalla erikoismuodoista on peruslajeista poikkeava runko tai versot. Pohjoiseen viherrakentamiseen soveltuu hyvin korallikanukka (Cornus alba 'Sibirica'), jonka punaiset versot ovat koristeelliset talven lumisessa maisemassa. Runko voi olla myös muulla tavoin poikkeava, kuten mukuraharmaalepällä (Alnus incana f. gibberosa). Tätä muhkuravartista, hidaskasvuista erikoisuutta on saatavilla myös pohjoisista taimistoista. Visakoivu (Betula pendula var. carelica) muhkuraisine runkoineen on koristeellinen-leveäkasvuinen pikkupuu. Visapihlajan (Sorbus aucuparia 'Pieksämäki) visaisuus ei näy mitenkään ulospäin puutarhan noin 20 vuotta vanhoissa puissa.

Kasvutavaltaan riippuvista, pylväsmäisistä sekä myös matalista peittopensaaksi soveltuvista kasveista on pohjoisessakin hyvin menestyviä muotoja ja lajikkeita, joista useita on myös kaupallisesti saatavilla. Näistä voidaan mainita esimerkkeinä riippapihlaja (Sorbus aucuparia 'Pendula'), pylväshaapa (Populus tremula 'Erecta'), pilaritervaleppä (Alnus glutinosa f. pyramidalis ja lajike 'Sakari') ja lamohietakirsikka (Prunus pumila var. depressa). Pylväskoivusta (Betula pubescens f. columnaris) on kasvamassa kaksikin paikallista kantaa. Pihlajista kapeakasvuisia ovat pylväspihlaja (S. aucuparia 'Fastigiata') ja Raahesta lisäykseen otettu kartiotaatanpihlaja ( $S . \times$ thuringiaca 'Fastigiata'). Hyvin yleinen koristepuu on myös terijoensalava (Salix fragilis 'Bullata'), jolla on pallomainen kasvutapa. Taivalkoskelta on löydetty riippahaapa ( $P$. tremula f. pendula) ja Oulusta riippaoksainen halava (Salix pentandra). Pyhäjärveltä löydetylle pensasmaiselle harmaalepälle tullaan ehdottamaan lajikenimeä 'Varjo' pensaan sateenvarjomaisen muodon vuoksi. Myös rauduskoivusta ja hieskoivusta kasvaa puutarhalla luonnosta löydettyjä pensasmaisia muotoja.

Myös kukan/kukinnon tai marjojen suhteen peruslajista poikkeavia kasveja kasvatetaan kasvitieteellisessä puutarhassa. Tähän ryhmään kuuluu pohjoisessakin yleisesti koristepensaana kasvatettu lumipalloheisi (Viburnum opulus 'Pohjan Neito'), jonka pallomaisten kukintojen kukat ovat steriilejä. Keltamarjapihlaja (Sorbus aucuparia 'Xanthocarpa') istutettiin syksyllä 2009 kasvitieteelliseen puutarhaan Oulun yliopiston 50-vuotisjuhlapuuna.

Havukasveista löytyy lukuisia erikoismuotoja ja viljelylajikkeita. Pohjoisilta taimistoiltakin on saatavissa useita katajan, kuusen, männyn ja tuijan lajikkeita, jotka poikkeavat perusmuodoista kasvutavaltaan tai neulasten väritykseltä. Pysty- ja kapeakasvuisia ovat mm. pilarikataja (Juniperus 
communis f. suecica) sekä pilarituija (Thuja occidentalis 'Fastigiata'). Pensasmaisia ovat isokasvuinen pallotuija (T. occidentalis 'Globosa') ja matala kääpiövuorimänty (Pinus mugo 'Pumilio'). Riippaoksaisia ovat riippakuusi (Picea abies f. viminalis) ja "riippaserbiankuusi" (P. omorika 'Pendula'). Oulusta on löydetty myös riippaoksainen mänty ( $P$. sylvestris f. pendula), jota ei ole vielä lisätty. Kääpiökatajilla (J. communis 'Repanda','Hornibrookii' ym.), pesäkuusella ( $P$. abies 'Nidiformis'), kääpiömustakuusella (P. mariana 'Nana') ja kääpiöserbiankuusella (P. omorika 'Nana') on mattomainen tai matala, kartiovalkokuusella ( $P$. glauca 'Conica') säännöllisen kartiomainen kasvutapa. Himalajankatajan (J. sqamata) sinertäväneulasisia lajikkeita ovat sinikatajat 'Blue Star' ja 'Blue Swede'. Hopeakuusen ( $P$. pungens f. glauca) terävät neulaset ovat sinivihreät. Kasvitietellisen puutarhan siemenistä kasvatetussa siperianlehtikuusikasvustossa (Larix sibirica) on yksi puu, jolla on sinertävät neulaset. Käpysikermämännyn (Pinus sylvestris f. conis) erikoisuutena on oksiin muodostuvat runsaskäpyiset rykelmät. Käärmekuusen (Picea abies f. virgata) erikoinen ulkomuoto harvaan haarottuneine oksineen on huomiota herättävä.

\section{Punalehtiset muodot, esimerkkinä punakoivu}

Punalehtisillä kasveilla punaisen värin aiheuttajana ovat erilaiset antosyyanipigmentit. Kasvista riippuen antosyaaniväritys voi olla joko koko kasvukauden pysyvä tai se on voimakkaimmillaan nuorissa tai vanhoissa lehdissä, jolloin kasvukauden aikana lehdet ovat vihreät tai vihertävän punaiset (Gould 2004, Nurmi 2008). Koristekasveiksi on erityisesti valikoitunut kasveja, joilla väritys on koko kasvukauden pysyvä. Luonnonkasveilla ns. "transient” eli väliaikainen antosyaaniväritys on yleisempi. Tavalliselle silmälle antosyaanit erottuvat kasvien lehdistä selvimmin syksyisen ruskan aikaan esim. pihlajissa sekä monissa ruusuissa. Vaikkakin antosyaanien synteesi on kasvien lehdissä geneettisesti säädelty, niin erilaiset ympäristötekijät kuten auringonsäteily, lämpötila sekä maaperän ravinteisuus vaikuttavat suuresti värin intensiteettiin (Gould 2004, Nurmi 2008). Antosyaanien tiedetään akkumuloituvan lehtiin myös erilaisina stressivasteina (Gould 2004).

Tunnetuin punalehtinen erikoismuoto pohjoisessa Suomessa on punakoivu, joka löydettiin vuonna 1978 Ylikiimingistä (Mäkirinta \& Similä 1980). Kauppi ja Ulvinen (1989) kuvasivat koivun tieteellisellä nimellä Betula pubescens Ehrh. forma rubra T. Ulvinen ja antoivat puulle suomenkielisen nimen punakoivu. Koska koivun lisääminen ei onnistunut perinteisin keinoin eikä puu tuohon aikaan tehnyt siemeniä, kehitettiin sille mikrolisäysmenetelmä Oulun yliopistolla kasvifysiologian tutkimusryhmän toimesta 1980-luvun lopulla. Tavoitteena oli saada monistettua materiaalia lähinnä tutkimustarkoituksiin ja mahdollisesti koristekasviksi. Ensimmäisen kerran mikrolisättyjen punakoivujen huomattiin tekevän siemeniä kasvitieteellisellä puutarhalla vuonna 1993. Tästä siemenerästä kasvaa seitsemän puuta kasvitieteellisen puutarhan taimistossa. Viimeksi punakoivun siemeniä on kerätty syksyllä 2008 ja näistä on kasvamassa 95 siemenjälkeläistä. Nämä taimet ovat arvokkaita jatkotutkimuksia varten. Punainen väri on koivuissa selvästi periytyvä ominaisuus, sillä kylvötaimista noin kaksi kolmasosaa on vihreitä ja yksi kolmasosa punalehtisiä. Spontaanisti itäneitä siementaimia on kesällä 2009 löytynyt kasvitieteellisen puutarhan kotimaan osastosta kaksi kappaletta. Puutarhalle on tullut myös muutama yleisöilmoitus punakoivun siementaimista.

Lehtien väritystä lukuun ottamatta punakoivu on pääosin hieskoivun kaltainen. Kasvutavaltaan punakoivu on ehkä aavistuksen verran harsumpi. Sen silmusuomut ovat voimakkaan punaiset ja kapeammat kuin hieskoivulla. Punakoivun lehdet puhkeavat vihreinä, tosin lehden reunat ovat jo hiirenkorvalla tummanpunaiset. Lehden auetessa ja kasvaessa täyteen mittaan punainen väritys leviää nopeasti koko lehteen. Punaisen värin aiheuttavat antosyaanit sijaitsevat punakoivun lehdessä pintakerroksessa eli epidermissä. Mikroskoopilla tarkasteltaessa lehden pinta näyttää mosaiikkimaiselta, sillä osa epidermin soluista säilyy vihreinä. Syksyllä lehtivihreän poistuessa lehdet ovat kirkkaamman punaisia. Vaikkakin värin kehitys etenee kasvukaudesta toiseen saman kaavan mukaisesti, vaihtelee värin intensiteetti, antosyaanipitoisuus, lehdissä eri vuosina (Kauppi \& Ulvinen 1989, Pihlajaniemi 2009). Punakoivun lehden pintakerroksessa olevat antosyaanipigmentit muuttavat lehden yhteyttävään solukkoon, mesofylliin, kulkeutuvan valon laatua. Punakoivun nuorissa lehdissä yhteyttämisnopeus on suurempi kuin täysikokoisissa, punaisissa lehdissä. Verrattaessa täysikokoisten puna- ja hieskoivun lehtien yhteyttämistä, on punakoivun yhteyttämisnopeuden todettu olevan hieman alhaisempi tai samaa tasoa kuin hieskoivulla (Portaankorva 1995, Pihlajaniemi 2009). Antosyaanien on esitetty liittyvän kasvien UV-B-säteilyltä suojautumiseen. Tutkittujen puna, hies- ja tunturikoivujen lehdissä kuitenkin UV-B alueella absorboivat pigmentit reagoivat kohonneeseen säteilyyn herkemmin 
(Pihlajaniemi ym. 2009, Pihlajaniemi 2009). Punakoivun, loimaankoivun, sulkaharmaalepän ja pylväshaavan menestymistä ja fenologiaa on tutkittu POHKAS - kenttäkokeissa neljällä eri koepaikalla Pohjois-Suomessa (Pihlajaniemi ym. 2007, Pihlajaniemi 2009). Näistä punakoivu menestyi kahdella pohjoisimmalla koepaikalla, Sallassa ja Rovaniemellä, tutkituista puista parhaiten. Punakoivun arvoa pohjoisessa viherrakentamisessa ei voi väheksyä, koska kestäviä punalehtisiä puiden erikoismuotoja on vähän. Punakoivua käytetään koristepuuna myös Ruotsissa.

\section{Lopuksi}

Erikoismuotoja voidaan käyttää tutkittaessa tietyn ominaisuuden ekologista merkitystä kasville sen kasvuympäristössä. Esimerkiksi antosyaanien toiminnallisesta tehtävästä kasvien lehdissä ei ole pystytty esittämään yksiselitteistä teoriaa, vaikka lukuisia hypoteeseja onkin julkaistu tieteellisessä kirjallisuudessa (Gould 2004). Punalehtisten kasvien, kuten punakoivun, avulla voidaan selvittää antosyaanien merkitystä yleisellä tasolla sekä spesifisesti pohjoisen kasvuympäristön valo- ja lämpöolosuhteisiin liittyen. Ekofysiologisten tutkimusten tuloksia voidaan hyödyntää myös käytännön viherrakentamisessa, kun esimerkiksi kasvuolosuhteiden merkityksestä erikoisominaisuuden ilmentymiseen saadaan tutkittua tietoa.

Pohjoisessa menestyvät puiden ja pensaiden erikoismuodot ovat arvokkaita viherrakentamisen kasvivalikoiman monipuolistamisessa. Näitä mielenkiintoisia kasveja löytynee vielä lisää kasvitieteellisten puutarhojen, puistojen ja arboretumien kokoelmista. Eniten niitä ehkä on odotettavissa kotimaisista puuvartisista kasveista. Muhoksella sijaitsevalla koealueella on kasvamassa erilaisia tuomiyksilöitä, jotka ovat poikkeavia kukinnon värin ja/tai koon tai lehtien väritykseltä (Uusitalo 2004). Mielenkiintoisia, uusia kasveja toimitetaan Oulun yliopiston kasvitieteelliseltä puutarhalta pohjoisille ja jopa kansainvälisille markkinoille erilaisten hankkeiden kautta. Puuvartisia kasveja, mm. vielä nimeämätön orapihlajan pylväsmäinen muoto (Crataegus "Pyramidalis”) ja kerrannaiskukkainen tuomi (Prunus padus f. plena) ovat lisäyksessä syksyllä 2009 alkaneessa New Plants for Northern Periphery Market-hankkeessa, jossa Suomesta ovat mukana MTT Kasvintuotanto Rovanimeltä ja Oulun yliopiston kasvitieteellinen puutarha

\section{Kirjallisuus}

Gould, K. 2004. Nature's swiss army knife. The diverse protective roles of anthocyanins in leaves. Journal of Biomedicine and Biotechnology 5: 314-320.

Hämet-Ahti, L., Palmén, A., Alanko, P. \& Tigerstedt, P.M.A. 1992. Suomen puu- ja pensaskasvio. Yliopistopaino. Helsinki. 373 s.

Kiuru, H. 2003. Liuskalehdet kiehtovat. [Botaniikkaa tarhurille.] Kotipuutarha 10/2006.

Kauppi, A. \& Ulvinen, T. 1989. Two new forms of Betula pubescens from Finland. Memoranda Societatis pro Fauna et Flora Fennica 65: 133-136.

Laine, K., Pihlajaniemi, H., Kananen, S., Siuruainen, M., Hämäläinen, A., Kauppila, T. \& Peteri, S-L. 2007. Pohjoisen matkailuympäristön kestävät kasvit. KalevaPrint Oy Oulu. 96 s.

Laine, K. \& Siuruainen, M. 2008. Oulun yliopiston kasvitieteellinen puutarha. - Teoksessa: Väre, H., Koponen, A., Hämet-Ahti, L., Hagman, M. \& Raisio, J. (toim.). Puiden jäljillä - 400 vuotta dendrologian historiaa. Dendrologian Seura. Helsinki. s. $176-180$.

Mäkirinta, A-M. \& Similä, A. 1980. Punalehtinen koivu Ylikiimingissä (PP). Luonnon Tutkija 84: 89.

Nurmi, L. 2008. Punaisen hehkua. Kodin Pellervo 9/2008.

Oskarsson, O. \& Nikkanen, N. 2001. Metsäpuiden erikoismuotoja kultakuusesta luutakoivuun. Metsäntutkimuslaitoksen tiedonantoja 670: 54 s.

Pihlajaniemi, H. 2009. Success of micropropagated woody plants under northern growing conditions and changing environment. Väitöskirja. Oulun yliopisto, Luonnontieteellinen tiedekunta, Biologian laitos. $82 \mathrm{~s}$.

Pihlajaniemi, H., Siuruainen, M., Rautio, P., Laine, K., Peteri, S-L. \& Huttunen, S. 2007. Successful growth of micropropagated ornamental tree forms in northern Finland. Dendrobiology 57: 63-71.

Pihlajaniemi, H., Järvenpää, E., Parbo, I., Huopalahti, R. \& Huttunen, S. 2009. Foliar anthocyanins in Betula pubescens f. rubra and the UV responses of three northern pubescent birch taxa. Käsikirjoitus. $34 \mathrm{~s}$.

Portaankorva, C. 1995. Punakoivun fotosynteesikyvystä ja sen rakenteellisista edellytyksistä. Gradu-tutkielma. Oulun yliopisto, Biologian laitos. $57 \mathrm{~s}$.

Ryynänen, L. \& Aronen, T. 2007. Koivun kirjavalehtisyys, periytyykö se sittenkin? Sorbifolia 38: 33-38.

Siuruainen, M., Alanko, P., Laine, K. \& Pihlajaniemi, H. 2004. Tieteellisten puutarhojen kokoelmat viherrakentamisen käyttökasvivalikoiman monipuolistajina. Teoksessa: Anneli Hopponen (toim.) Maataloustieteen Päivät 2004, 12.-13.1.2004. Suomen maataloustieteellisen seuran tiedote 19: 4 s. 
SUOMEN MAATALOUSTIETEELLISEN SEURAN TIEDOTE NRO 26

Uusitalo, M. 2004. Europen bird cherry (Prunus padus L.) - a biodiverse wild plant for horticulture. Agrifood Research Reports 61: 82 s. 